Muiraquitã, PPGLI-UFAC, v.2, n.1, Jul/Dez, 2013

\title{
A QUESTÃO DA LITERATURA: OBRA E AUTORIA EM MICHEL FOUCAULT
}

\author{
Miguel Ângelo Oliveira do Carmo \\ Universidade Federal do Acre - Brasil
}

\section{RESUMO}

O presente texto visa abordar a questão da literatura em Michel Foucault a partir de dois conceitos essenciais às suas análises: obra e autoria. Partindo de referências literárias que vão de Sade e Mallarmé à Georges Bataille e Maurice Blanchot, por intermédio dos conceitos de "transgressão" e "pensamento de fora", sem deixar de mencionar o "procedimento de escrita" de Raymond Roussel, o filósofo francês tece uma crítica à ideia da existência de um sujeito, de um autor por trás da escrita e toma a obra como o não-lugar da linguagem literária. Temos, assim, um outro conceito de literatura, que foge às definições tradicionais de enrijecimento não somente da escrita, mas também da linguagem em sua própria singularidade.

PALAVRAS-CHAVE: Literatura. Michel Foucault. Autoria. Linguagem.

No ano 2000, foi lançado aqui no Brasil um dos melhores estudos que visam dar conta da relação entre o pensador francês Michel Foucault e a literatura. O nome do livro é "Foucault, a Filosofia e a Literatura", do professor Roberto Machado. Como se vê pelo título, desde já o leitor poderá concluir que a relação entre a literatura e o pensador só poderia se dar pela filosofia. Esse encontro não é gratuito, pois durante algum tempo (anos 60), nas pesquisas arqueológicas sobre os saberes, a literatura teve uma função radical em para com a modernidade.

Após uma leitura e um estudo desse livro, tive a oportunidade de realizar uma pequena entrevista com o autor, na qual logo no começo procuro esclarecer o conceito de literatura ou de uso da literatura para Foucault. O entrevistado me responde:

Se digo que a literatura foi importante para Foucault é porque parece-me que ele a pensou como um contraponto ou mesmo uma 
alternativa aos saberes sobre o homem na modernidade. É assim que, se ele define a experiência literária como uma repetição própria da linguagem, essa ideia visava criticar a concepção moderna da linguagem como significação que é determinada na consciência, o que faz da consciência o fundamento, a condição da significação. É por isso que As Palavras e as Coisas, reapropriando-se de um termo de Roland Barthes, falará da intransitividade radical da linguagem literária, no sentido de, elidindo sujeito e objeto, ela estar inteiramente voltada sobre si mesma, inteiramente referida ao ato de escrever, querendo apenas afirmar sua existência, cintilar no brilho de seu ser (MACHADO, 1998).

A literatura foi um saber importante para Foucault não pelo fato de ter sido alçada às alturas em relação a tantos outros saberes, mas pelo fato de ter inerente à sua função uma crítica ao conhecimento moderno como solo de todas as significações. É preciso destituir a linguagem, neste caso, a linguagem literária, como o reino produtor dos sentidos atrelado à consciência. Desfeito esses grilhões mentais, a literatura pode apresentar-se como o lugar atravessado por uma relação mútua entre a linguagem e a obra. Se a linguagem lança palavras que se acumulam na história e cria sistemas de língua, a obra tece o espaço que retém o murmúrio dessas palavras ao longo da própria história. Temos um triângulo no qual a literatura é o vértice, sendo a linguagem e a obra as bases.

Nesse encontro triangular entre literatura, linguagem e obra, é preciso ver a relação entre linguagem e obra deixou de ser a partir do século XIX passiva, ou seja, não há mais um jogo entre o saber e a memória, a linguagem que produz saber e a obra que guarda para o futuro a memória do que foi dito. Agora, e é isso que caracteriza o deslocamento da literatura, ela passou a ser ativa e prática, passou a ter um desdobramento infinito consigo mesma, uma relação "obscura e profunda" que revela o seu ser em toda a sua espessura e traz a sua abertura diante da própria questão: "o que é a literatura?" 
Sade, Mallarmé, Rimbaud, Bataille, Blanchot, entre tantos outros, souberam como responder a essa questão que sinaliza a linguagem e a obra. Mas não tiremos dai relações dialéticas, como se a literatura fosse a linguagem em uma obra, e a obra, feita de linguagem. Lembremos que ela se posiciona no vértice de um triângulo e entre um lado e outro da base é preciso reter a pena, no ato da escrita, em uma "brancura essencial", em um desejo que se prolifera. Em uma conferência, pronunciada em Bruxelas em 1964 e intitulada "Linguagem e Literatura", Michel Foucault diz:

A literatura não é o fato de uma linguagem transformar-se em obra, nem o fato de uma obra ser fabricada com linguagem: a literatura é um terceiro ponto, diferente da linguagem e da obra, exterior à linha reta entre a obra e a linguagem, que, por isso, desenha um espaço vazio, uma brancura essencial onde nasce a questão 'O que é a literatura?', brancura essencial que, na verdade, é essa própria questão. Por isso, a questão não se superpõe à literatura, não se acrescenta a ela por obra de uma consciência crítica suplementar: ela é o próprio ser da literatura originariamente despedaçado e fraturado (FOUCAULT, 2000, p. 141).

Esse desejo não é a expressão de uma consciência, ele se quer fraturado, despedaçado, anônimo, ele quer ser um espaço vazio no qual não cabe a linguagem e a obra em suas formas indesejadas. Nessa nova empreitada literária, há uma voz murmurando infinitamente, despedaçada para todos os lados e, por isso mesmo, sem rosto, sem identidade, anônima em seu ocaso. Esse ser quer falar, mas não preso a uma obra, com seus ditos acostumados à poeira do tempo; ele quer mostrar seu rosto, mas para logo descobrirmos que é mais uma máscara. E então o que nos resta é a obra aberta, o eco dos ditos e um recomeço para a literatura. Cito:

Gostaria, ao menos, de apresentar a necessidade de abandonar uma ideia preconcebida - ideia que a literatura se fez de si própria segundo a qual ela é uma linguagem, um texto feito de palavras, palavras como as outras, mas suficientemente e de tal modo esco- 
lhidas e dispostas que, através delas passe algo inefável. Parece-me, ao contrário, que a literatura não é, absolutamente, feita de um inefável. Ela é feita de um não-inefável, de algo que, portanto, poderia se chamar de fábula, no sentido rigoroso e originário do termo. Ela é feita de algo que deve e pode ser dito; uma fábula que, todavia, é dita em uma linguagem de ausência, assassinato, duplicação, simulacro (FOUCAULT, 2000, p. 141).

Este começar de novo é um dito fabuloso, tão elevado sem eu sentido que passou a ser inventado, uma narração que para dizer algo necessita assassinar o não dito ou revirar-se ao avesso mostrando o seu outro lado, a sua ausência, a sua ausência de obra. Esse outro lado é também um simulacro da linguagem, uma invenção do homem inventado no limiar do século XVIII, que para disparar uma palavra ao infinito, faz uso da loucura contra a palavra infinita e representacional. Se a linguagem não carrega mais uma essência e a obra não deve ser tomada como o depósito do inefável, é porque o homem apresentou-se como possibilidade empírica da linguagem, fazendo-a explodir em mil sentidos, e a loucura como passou a ser vista como exemplo de obra inacabada. Para esquematizar um pouco, poderíamos concluir que existe, entre a literatura, por um lado, e a linguagem/obra, por outro lado, uma tensão, um paradoxo tensional, no qual o ser da literatura, precisando da linguagem e da obra, só se revela em um paradoxo além da relação entre linguagem e obra. Aqui, permitam-me forçar esse além: a literatura, na sua relação com a linguagem e com a obra, não é nem linguagem, no sentido acima colocado por Foucault, nem obra, pois a razão não é mais imperiosa.

Daqui, duas constatações, dois paradoxos, marcaram a ideia foucaultiana de literatura: a primeira, aquela que provém da linguagem; a segunda constatação, ligada a obra. A literatura não é a imposição brutal da linguagem, aquela que marca a sua essência e exige um direito à existência. É preciso manter uma distância entre a literatura e essa 
linguagem que se diz fundamento indizível: a "literatura é uma distância aberta no interior da linguagem, uma distância incessantemente percorrida e jamais coberta" (FOUCAULT, 2000, p. 142). A segunda constatação é que a obra só se torna literatura, obra literária, em seu exclusivo começo, no destaque da folha em branco ou na transgressão de uma sagração da literatura. Deve-se transgredir literatura em sua função representacional para reafirmá-la nesse espaço em branco como um ritual, um sacrifício criador, uma abertura para uma "experiência de transgressão" das palavras. Vejamos como Foucault nos apresenta isso:

Quando uma obra é literatura? O paradoxo da obra reside no fato de só ser literatura no exato momento de seu começo, na página em branco que permanece em branco, quando nada ainda foi escrito na sua superfície. O que faz com que a literatura seja literatura, que a linguagem escrita em um livro seja literatura, é uma espécie de ritual prévio que traça o espaço da consagração das palavras. (...) Por conseguinte, quando a página em branco começa a ser preenchida, quando se começa a transcrever palavras nessa superfície ainda virgem, cada palavra se torna de certo modo absolutamente decepcionante com relação à literatura, pois não há nenhuma palavra que pertença por essência, por direito de natureza, à literatura. De fato, desde que uma palavra esteja escrita na página em branco, ela deixa de ser literatura. Quer dizer que cada palavra real é de certo modo uma transgressão da essência pura, branca, vazia, sagrada da literatura que faz de toda obra não a realização da literatura, mas sua ruptura, sua queda, seu arrombamento. Qualquer palavra, prosaica ou cotidiana, sem status ou prestígio literário é um arrombamento, mas qualquer palavra desde que esteja escrita é, igualmente, um arrombamento (FOUCAULT, 2000, p. 142).

Tomo a liberdade, aqui, de levantar uma hipótese, a de que a literatura é ausência de literatura. Explico-me: o que comumente conhecemos por "literatura" é nada mais que o apagamento do escritor, do seu ser autoral, para pôr-se no lugar o próprio ser da literatura - e o que se ouve é a sua ânsia, o seu movimento pululante, a sua necessi- 
dade de se fazer existir, de se repetir, indefinidamente, na sua própria linguagem. Mais do que a escrita ou o reconhecimento autoral pela escrita, aquele que marca e determina para o escritor a "sua" palavra, a literatura é desejo ardente pela escrita. Desde o século XIX é característico de a literatura assassinar-se a si própria. Nesse sentido, o objetivo é limpar o espaço, o seu espaço, de toda e qualquer representação sagrada, infinita e primeira; o que ela assassina é a palavra primeira e coloca no seu lugar o seu murmúrio repetitivo, sem memória, longínquo da relação consciente e criadora da existência com a linguagem - somente falamos daquilo que podemos significar. Pelo contrário, a literatura como experiência transgressora, levando às últimas consequências o seu uso da linguagem, pretende ecoar o impensado, o que consideramos não existir - só pela linguagem é possível pensar (fazer existir) o impensado. Os exemplos literários estão em Sade, Hölderlin, Proust, Raymond Roussel, Maurice Blanchot, Georges Bataille, entre muitos outros. Com eles, a literatura tem como função agora fazer saltar esse poder da língua e da obra e transgredir o inefável, "rachar as coisas, rachar as palavras", realçar sua singularidade e impor uma autoria sem termos como crítica à cultura ocidental. Para termos presente essa literatura, tomemos como exemplo dois literatos, com seus respectivos conceitos: Maurice Blanchot e o "pensamento de fora", sem autoria possível; Raymond Roussel, com seu procedimento de escrita que desdobra o sentido e Georges Bataille, através do conceito de transgressão.

Nos anos 60, tentando se afastar do estruturalismo, Foucault, cada vez mais, trazia à tona o que entendia por "análise dos discursos", muito ligada à sua teoria do enunciado. A busca da não autoria seria apenas uma das imposições à crítica do sujeito, e nada melhor do que um novo tipo de literatura para a realização desse combate. A teoria do enunciado, com sua respectiva análise dos discursos, busca 
uma singularidade nos mesmos; nesse sentido o que importa são as descrições das condições de existência dos conjuntos significantes, as condições de formação dos discursos. Sobre o discurso, já em maio de 1968, Foucault escreverá:

O que eu analiso nos discursos não é o sistema de sua língua, nem de uma maneira geral as regras formais de sua construção, pois não me preocupo em saber o que o torna legítimo ou lhe dá sua inteligibilidade e lhe permite servir na comunicação. A questão que eu coloco é esta, não dos códigos, mas dos acontecimentos: a lei de existência dos enunciados, isso que os tornou possíveis - eles e nenhum outro em seu lugar; as condições de sua emergência singular; sua correlação com outros acontecimentos anteriores ou simultâneos, discursivos ou não (FOUCAULT, 2001a, p. 709).

Essa análise tomará corpo na história e pela história; e aqui ou a partir daqui, mais uma vez, é preciso manter as diferenças. "O que Foucault faz é história das ideias", dirão uns; "o que ele quer mostrar é o fundamento silencioso dos discursos, a sua consciência fundadora", escreverão outros; "ele traz à tona as estruturas do discurso", insistirão ainda. Nem um nem outro discurso parece dar conta do que realmente Foucault fez. Sua prática se aproxima de uma história que interrogue o acontecimento do discurso:

Eu não escrevo uma história do espírito, segundo a sucessão de suas formas ou a espessura de suas significações sedimentares. Eu não interrogo os discursos sobre o que, silenciosamente, eles querem dizer, mas sobre o acontecimento e as condições de sua aparição manifesta; não sobre os conteúdos que eles podem esconder, mas sobre as transformações que eles efetuaram; não sobre o sentido que se mantém neles como uma origem perpétua, mas sobre o campo onde eles coexistem, habitam e se afastam. Trata-se de uma análise dos discursos na dimensão de sua exterioridade (FOUCAULT, 2001a, p. 710).

"Trata-se de uma análise dos discursos na dimensão de sua exterioridade" - o que devemos entender por isso? O que significa tentar 
localizar os discursos, seus enunciados, no exterior, no fora que lhes pertence? Qual o lado de fora do discurso e fora a que? Parece-nos que a compreensão do conceito de "pensamento de fora", em Foucault, passa pela busca do acontecimento do discurso e remete essa idéia para outro estilo de pensar o acontecimento, já imbuído das relações de poder ${ }^{1}$. Em 66, Foucault publica em Critique um texto consagrado ao escritor Maurice Blanchot, no qual ele define o que chamou de "pensamento de fora". Na verdade, era este a grande imagem de uma linhagem marginal (Sade, Nietzsche, Hölderlin, Artaud) que não cansa de corromper os fundamentos da representação, da consciência cartesiana, do "eu penso". Contra tudo isso a palavra fala, ou seja, a "linguagem ao infinito", o vazio da linguagem porque "o sujeito que fala é o mesmo que aquele pelo qual ele é falado"; se o sujeito que fala, no próprio ato da fala, cava esse vazio não é para nada fazer aparecer, mas tornar evidente o que já está lá, o "ser da linguagem" em sua existência própria e singular. O desaparecimento do sujeito só pode ser o aparecimento do ser da linguagem em um exterior no qual a regra da própria linguagem não tem morada - eis sua característica principal. Mas que pensamento é esse que anula o sujeito e deixa pairando no ar a palavra por si só, em "jorro infinito"?

Esse pensamento que se mantém fora de toda subjetividade para dele fazer surgir os limites como do exterior, enunciar seu fim, fazer cintilar sua dispersão e acolher apenas a invencível ausência, e que ao mesmo tempo se mantém no limiar de toda positividade, não tanto para apreender o fundamento ou a justificação, mas para reencontrar o espaço em que ele se desdobra, o vazio que lhe serve de lugar, a distância na qual ele se constitui e onde se esconde suas certezas

1 Essa ideia pode ser encontrada em Judith Revel: "Será somente bem mais tarde que Foucault deixará de pensar o 'exterior' como uma passagem ao limite ou como uma pura exterioridade, e que ele lhe dará um lugar no seio mesmo da ordem do discurso: a oposição não será, portanto, mais entre o dentro e o fora, entre o reino do sujeito e o murmúrio anônimo, mas entre a linguagem objetivada e a palavra de resistência, entre o sujeito e a subjetividade, isto é, aquilo que Deleuze chamará 'a dobra"” (2005, p. 51). 
imediatas, assim que ali se lance o olhar, um pensamento que, em relação à interioridade de nossa reflexão filosófica e à positividade de nosso saber, constitui o que se poderia chamar "o pensamento de fora" (FOUCAULT, 2001a, p. 549).

Aqui a reflexão perde de vista a consciência, como fundamento do sujeito, e toda a interioridade se encontrará aberta, "atraída para fora de si" na impossibilidade de um EU. É Blanchot que, para Foucault, representa hoje a impossibilidade da consciência nas palavras de um discurso; foi ele quem convidou e atraiu o pensamento para uma experiência por vezes negligente. Negligente com o que? Com as figuras da interioridade. Não se busca mais o segredo imanente em um texto, a verdade nas entrelinhas à espera de seu resgate, mas relações sempre novas entre as palavras, as metáforas e as narrativas possíveis do texto; essas relações não são determinações de um autor, mas desdobramentos da própria linguagem textual. É nesse sentido que a crítica literária representada por Blanchot marca o exterior da literatura e culmina com toda e qualquer interioridade insistente. Vejamos uma longa passagem na qual Foucault atribui essa façanha à figura desse escritor:

Foi Blanchot quem tornou possível qualquer discurso sobre a literatura. De início, porque ele foi o primeiro a mostrar que as obras se conectam umas com as outras por essa face exterior de sua linguagem na qual surge a literatura. A literatura é, assim, o que constitui o fora de qualquer obra, o que sulca toda linguagem escrita e deixa em qualquer texto a marca vazia de uma ranhura. Ela não é um modo de linguagem, mas um vazio que percorre como um grande movimento todas as linguagens literárias. Fazendo aparecer essa instância da literatura como "lugar comum", espaço vazio onde vêm se alojar as obras, creio que ele assinalou à crítica contemporânea qual deve ser seu objeto, o que torna possível seu trabalho ao mesmo tempo de exatidão e de invenção.

E, continuando, não deixa de afirmar esse discurso anônimo que liberta o ser da linguagem do poder de um autor:

Pode-se afirmar, por outro lado, que Blanchot a tornou possível ins- 
tituindo entre o autor e a obra um modo de relação até então insuspeitado. Sabe-se agora que a obra não pertence a um projeto de seu autor, nem mesmo àquele de sua existência, que ela mantém com ele relações de negação, de destruição, que ela é para ele o jorro do eterno fora, existindo, no entanto, entre eles essa função primordial do nome. É pelo nome que, em uma obra, se marca a modalidade irredutível do murmúrio anônimo de todas as outras linguagens. Não há dúvida de que a crítica contemporânea ainda não questionou verdadeiramente essa exigência do nome que Blanchot lhe propôs. Será preciso que ela se preocupe com isso, já que o nome marca para a obra suas relações de oposição, de diferença com outras obras, e caracteriza totalmente o modo de ser da obra literária em uma cultura e em instituições como as nossas. Afinal, há séculos, seis ou sete, que o anonimato, salvo caso excepcional, desapareceu inteiramente da linguagem literária e de seu funcionamento (FOUCAULT, 2001a, p. 621). ${ }^{2}$

No entanto, é preciso observar que a experiência de um pensamento de fora, além de Blanchot, já vinha sendo esboçada em outras literaturas contemporâneas. O procedimento de desdobramento literário de Raymond Roussel e o conceito de transgressão em Georges Bataille já fascinavam Foucault no início dos anos 60.

Qual é o procedimento de Roussel, que tanto fascinou Foucault e o fez lhe dedicar um livro, único livro (Raymond Roussel) sobre literatura a ser escrito pelo filósofo? Era tudo um jogo, um jogo de linguagem que passava pela diferença e pela repetição. De uma palavra nascerá outra que lhe é próxima, mas que o sentido criado a fará manter distância. A criação será aleatória, pois virá de acordo com a combinação livre e arbitrária dada ao texto em toda a sua formulação. O procedimento é a criação multiforme e invisível das palavras que dão nascimento às outras, ao mesmo tempo em que mantém certa visibilidade sobre as coisas. Roussel brincou com a linguagem mantendo/ revelando um segredo que nos encanta. Para Foucault,

2 Para outra declaração sobre esse tipo de pensamento que anula o sujeito como autor literário a partir de Blanchot, confira "Interview avec Michel Foucault”, Dits Et Écrits I, 2001a, p. 688. 
O encantamento não está ligado a um segredo depositado nas dobras da linguagem por uma mão exterior; ele nasce das formas próprias a essa linguagem quando ela se desdobra a partir dela mesma segundo o jogo de suas possíveis nervuras. (...) O enigma de Roussel é que cada elemento de sua linguagem está preso a uma série não enumerável de configurações eventuais (FOUCAULT, 2001a, p. 239). ${ }^{3}$

A experiência de Roussel, o desdobramento das palavras, obriga a linguagem, em suas "configurações eventuais", a uma abertura característica de um pensamento sem fundamento.

Em Georges Bataille, ou melhor, na sexualidade posta ao limite pelos seus próprios personagens, Foucault encontrou um pensamento da transgressão, mas que depois, vale chamar a atenção, com os deslocamentos nas análises do poder, acreditamos poder dizer o seguinte: o combate não se dará mais pelo uso do conceito de transgressão, principalmente pela via literária, que deixará de figurar em suas pesquisas, mas pelo aprimoramento em uma ação tática de resistência aos poderes infinitos e aos processos de subjetivação. Se Foucault, nos anos 60 , encontrou na literatura a palavra de ordem para uma transgressão dos saberes que dominam e fazem dominar, será mais tarde que ele perceberá a necessidade de um trabalho político-estratégico no enfrentamento do saber-poder e que permita um "deslocamento" (déplacement) contínuo às regras do jogo do real.

Mas, também, não podemos pensar que para Foucault a transgressão, que se somava aos trabalhos literários de Blanchot, Sade e Klossowski, apesar de seu deslocamento para combater o poder, tinha um caráter de negação e/ou oposição. Ter a experiência do limite na finitude ontológica do ser não era a afirmação de uma negação sem-

3 Esse texto é uma preparação para o livro citado. Para mais, veja o capítulo "O umbral e a chave" (FOUCAULT, 1999). Encontraremos outra explicação do procedimento literário de Roussel na entrevista “Archéologie d'une passion”, Dits et Écrits II, 2001b, pp. 1421-1422. 
pre firme contra uma determinada realidade, mas de uma liberação existencial naquilo que lhe é mais peculiar: a vida enquanto diferença possível. Portanto, nenhuma negação:

A transgressão não opõe nada a nada, não faz nada deslizar no jogo da ironia, não procura abalar a solidez dos fundamentos; não faz resplandecer o outro lado do espelho para além da linha invisível e intransponível. Porque, justamente, ela não é violência em um mundo partilhado (em um mundo ético) nem triunfa sobre limites que ela apaga (em um mundo dialético ou revolucionário), ela toma, no coração do limite, a medida desmesurada da distância que nela se abre e desenha o traço fulgurante que a faz ser. Nada é negativo na transgressão (FOUCAULT, 2001a, p. 266).

No entanto, naquela época, o que significava transgressão para Foucault? É no texto em homenagem a Bataille que o conceito fica bem claro quando se trata dessa sexualidade que fissura para traçar nosso limite, nossa finitude. Então a questão se coloca: "Ora, uma profanação em um mundo que não reconhece mais sentido positivo no sagrado, não é mais ou menos isso que se poderia chamar de transgressão?" (FOUCAULT, 2001a, p. 262). A referência à "morte de Deus" é clara e é dela que tiramos a experiência interior de nossa finitude. Sem Deus estamos abertos a tomar a vida pelo que ela é; a fazer da nossa linguagem aquela que não sustenta nenhum sujeito, nenhuma consciência, nenhuma morada.

O que nos trazem esses literatos da modernidade? Que linguagem é essa que dá nascimento à literatura e permite, junto com uma determinada forma de filosofar, uma crítica ao sujeito? No momento em que se definiu a palavra do infinito, a cultura ocidental se desviou da palavra sagrada e abriu caminho para a derrocada da subjetividade filosófica, garantindo não o fim da filosofia, mas a sua abertura mais radical para pensar o acontecimento. Foucault chamou a atenção para isso, quando assinalou o surgimento da literatura:

Tenho a impressão de que nessa relação da linguagem com sua in- 
finita repetição uma mudança se produziu no fim do século XVIII - quase coincidindo com o momento em que a obra de linguagem se tornou o que ela é agora para nós, ou seja, literatura (FOUCAULT, 2001a, pp. 282-283).

A linguagem ao infinito como prática filosófica foi, até certo momento, o jogo de Foucault para não só para tratar o acontecimento no discurso, mas para mantê-lo como crítica do sujeito na contemporaneidade. Discurso que fala o acontecimento, portanto anônimo e sem sujeito.

Com esses escritores, Foucault vislumbrou outra forma de se fazer literatura, sem sujeito, sem autoria, elementos em total relação. Mas, então, o que podemos entender com o fato de ser autor? Em 1969, Michel Foucault realiza uma conferência para a Sociedade Francesa de Filosofia, com o sugestivo título "O que é um autor?" [Qu'est-ce qu'un auteur?]. Essa apresentação não só se pautou pelas incompreensões ocasionadas pelo livro As Palavras e as Coisas, que ele tentou dar conta com o lançamento de outro livro: A Arqueologia do Saber, mas também teve como intuito atacar a ideia tão insistente de uma interioridade da literatura, na qual o autor, o escritor se quiser, viria a se alojar e garantir toda a determinação do seu discurso. Trata-se de afirmar e liberar toda uma exterioridade que se encontrou na literatura, como também, através de uma não individualização do discurso, a evidência da existência de relações, de sistemas, de feixes que perpassam o funcionamento do discurso. Tudo isso vem à tona quando se analisa a chamada "função autor". O que podemos entender por isso e qual a sua relação com a questão do sujeito?

A conferência “Qu'est-ce qu'um auteur?” traz a noção de "autor” e procura mostrar em que sentido ela está revestida de procedimentos que caracterizam o modo de ser do discurso ou daquele que fala. $\mathrm{Ou}$ seja, o discurso, falado ou escrito, através dos seus mecanismos, visa 
nada mais que a garantia de um status àquele que fala ou escreve, ao seu autor. É este o conceito de autor que nos impede de ver a sua real função. Aceitar a existência de um autor para todo e qualquer discurso é legitimar as operações complexas de criação do próprio discurso, é não se aperceber da relação do poder discursivo com todo um sistema e institucionalização da própria linguagem. Nesse sentido, a afirmação de uma proliferação discursiva (a sua exterioridade) e do ser da linguagem, ausente de uma relação possível com o indivíduo, permite não só descaracterizar a função autor de uma "ordem do discurso" como mostrar os modos, as regras, do que se convencionou chamar autor.

A crítica à função autor é inerente à ideia de sujeito, pois traça o mesmo caminho. Se o autor é, ao mesmo tempo, o produto e a manutenção de uma ordem do discurso, o sujeito, em sua narração histórica, encontra os mesmo preceitos. Sendo assim, o que conhecemos como "homem" não seria mais a confirmação forçada de um sentido originário do que o resultado de certo uso da linguagem? "Que importa quem fala?" Talvez o mais importante fosse tentarmos perceber como se fala. Acusado da morte do homem, Foucault tenta explicitar na conferência citada, de maneira irônica, não só sua crítica à questão do sujeito, mas também a sua relação com a noção de autor. Diz ele:

a morte do homem é um tema que permite revelar a maneira pela qual o conceito de homem funcionou no saber. [...] Não se trata de afirmar que o homem está morto, mas a partir do tema - que não é meu e que não parou de ser repetido após o final do século XIX - que o homem está morto (ou que ele vai desaparecer ou será substituído pelo super-homem), trata-se de ver de que maneira, segundo que regras se formou e funcionou o conceito de homem. Fiz a mesma coisa em relação à noção de autor. Contenhamos então nossas lágrimas (FOUCAULT, 2001a, p 845).

Para o autor, antes de se declarar sua morte, percebamos em que 
sentido apareceu e funcionou o discurso sobre o mesmo. É através da sua análise histórica que colocamos em jogo os seus modos de existência, com seus respectivos sujeitos sedimentados. A suspensão da ideia do autor reclama uma proliferação do sentido também como subversão do sujeito. É preciso desalojá-lo das suas dependências confortáveis em prol da percepção da singularidade do discurso, das modalidades de existência do mesmo em sua exterioridade histórica. Nessa análise:

Trata-se de inverter o problema tradicional. Não mais colocar a questão: como a liberdade de um sujeito pode se inserir na espessura das coisas e lhes dar sentido, como ela pode animar, do interior, as regras de uma linguagem e manifestar assim as pretensões que lhe são próprias? Mas antes colocar essas questões: como, segundo que condições e sob quais formas alguma coisa como um sujeito pode aparecer na ordem dos discursos? Que lugar ele pode ocupar em cada tipo de discurso, quais funções exercer e obedecendo a quais regras? Trata-se, em suma, de retirar do sujeito (ou do seu substituto) seu papel de fundamento originário, e de analisá-lo como uma função variável e complexa do discurso (FOUCAULT, 2001a, pp. 838-839).

O sujeito e o autor aparecem então como funções provenientes do poder do discurso, produto do complexo saber-poder. Se por um lado o autor perde o seu estatuto, o seu papel, diante da função de poder que ele exerce em seu discurso, por outro não façamos dessa crítica uma negatividade diante da prática literária. A demolição do império do discurso visa fazer emergir uma positividade da experiência trágica no ato de escrever, pois ler os textos dos grandes escritores (Homero, Aristóteles, Freud ou Marx) é perceber toda a proliferação configurativa dos seus próprios discursos e das regras de formação dos outros textos, ao mesmo tempo em que dá à linguagem e à escrita todo o seu ser, todo o seu modo de liberdade diante da suas clausuras. Diz Foucault:

O nome de autor serve para caracterizar um certo modo de ser do discurso: para um discurso, ter um nome de autor, o fato de se poder 
dizer "isto foi escrito por fulano", indica que esse discurso não é um discurso cotidiano, indiferente, um discurso flutuante e passageiro, imediatamente consumível, mas que se trata de um discurso que deve ser recebido de certa maneira e que deve, numa determinada cultura, receber um certo estatuto. [...] O nome de autor não está situado no estado civil dos homens nem na ficção da obra, mas sim na ruptura que instaura um certo grupo de discursos e o seu modo de ser singular. [...] A função autor é, assim, característica do modo de existência, de circulação e de funcionamento de alguns discursos no interior de uma sociedade (FOUCAULT, 2001a, p. 826).

Se a escrita e a obra, o seu discurso, a sua linguagem, são reverberações de modos de existência, então é preciso fazer a literatura cintilar em sua experimentação. A finitude do homem, o seu possível desaparecimento, o encontro (da escrita) com a morte e a loucura são provas de que a literatura moderna não parou de se inventar. Podemos dizer mais, não parou de encarar tragicamente a vida. Deleuze dizia que era preciso fazer a língua gaguejar - a literatura americana, para ele, gaguejava. Da língua para o gaguejo, da escrita para a reescrita anônima. Do traço reto para os desvios. Não eternizemos o sentido, multipliquemos o sentido, o limiar do sentido. É preciso se insurgir contra essas paralisias da subjetividade, perceber a palavras no vazio, na abertura da sua valoração, na violência silenciosa do que ela vem a ser. Por trás de um sentido imposto há um sentido por fazer-se, uma realização possível, uma imaginação a abrir-se e um "risco" a correr. A escrita sempre é duplamente perigosa: um perigo subjetivamente transformativo e um risco, um traço, que recusa determinados caminhos. Talvez por isso a literatura esteja sempre em processo de risco, de rabisco e de riso - um risco de autoria, um rabisco de apagamento e um riso para recomeçá-la. Sem meio termo, tenta-se uma literatura do porvir, que a deixo na exigência do próprio filósofo. Ele diz: "Não me perguntem quem eu sou e não me digam para continuar o mesmo: esta é uma moral de estado civil; ela rege nossos papéis. Que ela nos deixe livres quando se trata de escrever". 
Muiraquitã, PPGLI-UFAC, v.2, n.1, Jul/Dez, 2013

THE QUESTION OF LITERATURE: WORK AND AUTHORSHIP IN MICHEL FOUCAULT

\section{ABSTRACT}

This text is intended to discuss literature in Michel Foucault under two key concepts to his analysis: work and authorship. Having in mind literary references that range from Sade and Mallarmé to Georges Bataille and Maurice Blanchot, through his concepts of "transgression" and "the thought from outside", not to mention the "writing procedure" Raymond Roussel, the French philosopher criticizes the idea of the existence of a subject, an author behind the writing, and establishes the work as the non-place of literary language. We thus have another concept of literature, that flees from the traditional definitions of stiffness of writing, and even of the language in its own uniqueness.

KEYWORDS: Literature. Michel Foucault. Authorship. Language.

\section{REFERÊNCIAS}

FOUCAULT, M. Linguagem e literatura, In: MACHADO, R. Foucault, a Filosofia e a Literatura. Rio de Janeiro: Jorge Zahar Editor, 2000. pp. 137-174.

FOUCAULT, M. Raymond Roussel. Trad. De Manoel de Barros da Motta e Vera Lucia Avellar Ribeiro. Rio de Janeiro: Forense Universitária, 1999. FOUCAULT, M. A Arqueologia do saber. Trad. de Luiz Felipe Baeta Neves. Rio de Janeiro: Forense Universitária, 1997.

FOUCAULT, M. Réponse à une question. In: Dits et Écrits I (1954-1975). Paris: Éditions Gallimard, 2001a.pp. 701-723.

FOUCAULT, M. La pensée du dehors. In: Dits et Écrits I (1954-1975). Paris: Éditions Gallimard, 2001a. pp. 546-567.

FOUCAULT, M. Sur les façons d'écrire 1'histoire. In: Dits et Écrits I (1954-1975). Paris: Éditions Gallimard, 2001a. pp. 613-628. FOUCAULT, M. Interview avec Michel Foucault. In: Dits et Écrits I (1954-1975). Paris: Éditions Gallimard, 2001a. pp. 679-690. FOUCAULT, M. Dire et voir chez Raymond Roussel, In: Dits et Écrits I (1954-1975). Paris: Éditions Gallimard, 2001a. pp. 233-243. FOUCAULT, M. Préface à la transgression. In: Dits et Écrits I (1954- 
1975). Paris: Éditions Gallimard, 2001a. pp. 261-278.

FOUCAULT, M. La langage à l'infini. In: Dits et Écrits I (1954-1975).

Paris: Éditions Gallimard, 2001a. pp. 278-289.

FOUCAULT, M. Qu'est-ce qu'un auteur? In: Dits et Écrits I (1954-1975).

Paris: Éditions Gallimard, 2001a. pp. 817-849.

FOUCAULT, M. Archéologie d'une passion. In: Dits et Écrits II (19541975). Paris: Éditions Gallimard, 2001b. pp. 1418-1427.

MACHADO, R. Uma entrevista com Roberto Machado. CARMO, Miguel Ângelo Oliveira do. Verbo 21, 1998, disponível em httplwww.verbo21.com.br/arquivo/13tx1.htm

REVEL, J. Foucault: conceitos essenciais. São Carlos: Editora Claraluz, 2005. 